\title{
A brief review on PADI encyclopedia of recreational diving
}

\author{
Mostafa Ali Biegi ${ }^{1, ~}{ }^{*}$, Elahe Abdoos ${ }^{2}$ \\ ${ }^{1}$ Young Researchers and Elite Club, Firoozkooh Branch, Islamic Azad University, Firoozkooh, Iran \\ ${ }^{2}$ Department of Industrial Engineering, Eyvanekey Institute of Higher Education (Nonprofit- Nongovernmental), Eyvanekey, Iran
}

\section{Email address:}

mostafaalibeigi@gmail.com (M. A. Beigi), elaheabdous@gmail.com (E. Abdoos)

\section{To cite this article:}

Mostafa Ali Biegi, Elahe Abdoos. A Brief Review on PADI Encyclopedia of Recreational Diving. American Journal of Life Sciences. Special Issue: Recent Researches in Diving and its Relations with Mathematics. Vol. 3, No. 3-1, 2015, pp. 1-11.

doi: 10.11648/j.ajls.s.2015030301.11

\begin{abstract}
Diving is one of the extremely excitement and recreation in the world. Every year, many people are going to trip for diving, and they are certainly pleasing memories of the trip will be. In the meantime, exiting "safety", "comforting", "reliability" and etc are very important for fun and professionals divers and it's clear why. In other hand, diving can make good memories, when do not exist any casualty arising from the lack of regulation. Therefore, it is necessary to study and knowing rules and general information of diving. In this paper, we a brief review on PADI encyclopedia of recreational diving, which will be useful for the researchers who are professional and interested in this area, and also useful for person who have fun dive. We describe advantages of knowing each section throw of that section.
\end{abstract}

Keywords: Life Science, Diving, PADI Encyclopedia of Recreational Diving, Diving Technology, Professional Association of Diving Instructors (PADI), Excitement and Recreation

\section{Introduction}

In the history, men were engaged in underwater commerce, salvage and military activities and to expand the frontiers of knowledge through exploration and research. No one knows when man first discovered he could go under water by holding his breath, but diving as a profession can be traced back to more than 5000 years.

These early divers efforts were restricted to shallow waters (less than 100 feet), with the divers collecting food, sponges, coral and pearl that were commercially valuable. One of the first records of such diving is found in the writings of the Greek historians, "Herodotus". He tells the story of a diver called Scyllis, who was working for the Persian king Xerxes to recover sunken treasure in the fifth century B.C. From the earliest times, divers were active in operations. Their mission was cutting anchor cables of enemy ships adrift, boring or hunching holes in the bottoms of enemies ship's and building harbor defenses at their harbors then attempting to destroy defense support of enemy.

Other early divers developed salvage industry focused on the major shipping ports of the eastern Mediterranean.

The most obvious and necessary means in increasing the capabilities of a diver underwater was to provide an air supply. First they used hollow reeds or tubes extending, their head to the surface. The user could remain submerged for a long time but couldn't accomplish well.

Breathing tubes were employed mainly as a tactic in military operations where they permitted an undetected approach to an enemy border, but by these tubes the divers couldn't go to deep areas.

In an Assyrian frieze ninth century B.C, a diver is shown using inflated animal skins as air tanks. This idea is very old and these men were swimmers using skins for floating. It would be impossible to submerge while holding such instrument.

In the late middle ages, a workable diving system was observed. In 1240, Roger Bacon made a reference for instruments, which men could walk on sea or river beds without any danger. In the sixteenth and seventeenth centuries, some researchers explained and published a sample of equipment which emphasized on later successful developments.

Between 1500 and 1800, the diving bell was developed, enabling divers to remain underwater for hours.

The diving bell is bell-shaped with the bottom open as a strong and wide box. The first diving bells were strong tubes to sink in a vertical position keeping enough air to permit a diver to breathe for several hours. The principle of the bell is easily observed by pushing an inverted glass into water. 
Diving bells are suspended by a cable from the ship and have no underwater maneuverability than moving the ship. The diver can remain in the bell, or by holding his breath can go outside for short period of time.

The first scientific use of diving bell was made in 1531 and for several years, primary bells were used regularly. In the 1680s, an adventurer named William Phipps from Massachusetts modified the diving bell technique by supplying his divers with air from series of heavy, inverted buckets in order to recover treasure valued at $200,000 \$$.

\subsection{A Review of Training PADI System (the Professional Association of Diving Instructors (PADI))}

The Professional Association of Diving Instructors with more than 40 years of experience was founded in 1966 by two divers of America navy named John Cronin and Ralph Erickson with the aim of diving training by new methods without military operations that was common on that period. This institution by new teaching methods and American training system and with the collaboration of many universities all over the world and using hospitability methods of hotels to give services to the tourists, attempted to design a new method in diving training and the results are the increasing development of this recreation among the modern and advanced societies and communities in the world. This institution acquired $75 \%$ of total diving training in all over the world.

Today, this institution with 5300 diving centers in 180 countries in the world and about 130,000 skillful instructors plays an important role in global tourism industry by giving safe and efficient diving activities all over the world and presented a new standard in ecotourism and above all safety motto and it is also accepted by many people in the world.

\subsubsection{Why PADI}

PADI Divers carry the most respected and sought after scuba diving credentials in the world. No matter where you choose to dive, your PADI certification card will be recognized and accepted. In fact, on most scuba diving adventures, you'll be surrounded by other PADI Divers who made the same certification choice you did - to train with the world's largest and most respected scuba diving training organization.

\subsubsection{How is PADI Different}

Education - The PADI System of diver education is the most instructionally solid system in diving. PADI courses are designed to make learning enjoyable and worthwhile. Under the guidance of your professional PADI Instructor, you gain confidence while mastering important safety concepts and skills. PADI Instructors are trained and held to diving's highest standards, backed up by a solid, proactive quality management system.

Performance-Based Learning - You progress at your own pace as you demonstrate mastery of specific performance requirements essential to becoming a scuba diver. You must earn your PADI certification, but you do so in an encouraging and well-supported learning environment.

Educational Materials - Credentialed instructional designers use state-of-the-art technology and learning theories to create PADI materials with you, the student diver, in mind. Independent study materials, available in a variety of media online programs, tablet-based apps, manuals, workbooks, multimedia discs, etc. - allow you to learn in a way that works for you. Instructional support materials allow your PADI Instructor to further explain important concepts and verify understanding.

Educational Standards - All PADI programs, from entry-level through scuba instructor training, fall under strict educational standards monitored for worldwide consistency and quality. PADI takes a proactive approach to quality management and randomly surveys PADI Divers to confirm their courses meet PADI's high standards as well as the divers' expectations. No other diver training organization works to maintain this level of professional reliability and integrity.

Continuing Diver Education - The fun and enjoyment of being a confident scuba diver is fueled by continuing to improve your scuba skills. Each PADI course builds on the previous one, teaching you skills and techniques when you're ready to learn them. PADI specialty courses let you explore specific dive interests. Professional-level courses let you live the scuba diving lifestyle by becoming a divemaster or scuba instructor.

\subsection{Environmental Responsibility}

As a PADI Diver, you join millions of others to form a growing force that can and does make a difference in the effort to preserve the underwater world. PADI courses encompass environmental awareness and protection philosophies that emphasize the importance of protecting fragile aquatic ecosystems. The worldwide PADI organization is committed to preserving the aquatic environment for future generations. Diving won't survive without beautiful places to visit, and PADI Divers are encouraged to take action with Project AWARE and make every dive count for a clean, healthy ocean planet.

\subsection{PADI Today}

In 2003, John Cronin passed away. His friend and PADI co-founder, Ralph Erickson, passed away three years later. They proudly carried PADI's torch for many years before they confidently put it in the hands of today's generation of PADI Professionals, who continue to introduce the world to scuba diving.

With close to 400 employees in PADI corporate offices around the world, the PADI organization works hard to be the best partner to its members and is committed to:

- Safe and responsible diver acquisition and retention.

- Quality member acquisition and retention.

- Financial prosperity.

- Worldwide alignment in message, products, systems and procedures.

The PADI Worldwide Executive team, led by Dr. Drew 
Richardson, President and CEO, ensure these promises are met.

From above, we uses encyclopedia of recreational diving that PADI published.

In this paper, we a brief review on PADI encyclopedia of recreational diving, which will be useful for the researchers who are professional and interested in this area, and also useful for person who have fun dive.

The present study is organized as follows: Section 2, contains the diving equipments as basic definitions and notations that will be used for all divers. Section 3, includes Physics of Diving. The Physiology of Diving are presented in section IV, The paper is concluded in Section V.

\section{Diving Equipments}

In this section, we brief describe of diving equipments, that it is important for having great diving. Advantages about following texts are clear.

In the early days of diving, the equipment was primitive and there wasn't much to choose from in what there was. The more your physique departed from that of an average-sized physically fit young male, the more likely you had difficulty finding something that fit well. Happily, those days are far behind us. Today almost anyone, regardless of size, shape or gender, can find comfortable dive gear that fits. It's also lighter, more attractive and has higher performance than earlier gear.

The Fully Equipped Recreational Diver as following:

- Mask: Traps air around eyes so you can see.

- Snorkel: Used at surface to allow breathing in waves or face in water without using air from the cylinder.

- Regulator: Delivers air from cylinder when you inhale.

- Alternate air source: An extra regulator for sharing air with another diver in an emergency.

- SPG Submersible Pressure Gauge: shows you how much air you have left.

- Cylinder: Holds high pressure compressed air.

- Exposure suit: Provides insulation for a comfortable dive (different types for different water temperatures).

- Fins: Provide a broad surface area for your legs to push against, allowing you to swim without using your hands.

- Cutting tool: (not visible) Safety device for freeing yourself in case of entanglement.

- BCD - Buoyancy Compensating Device: uses air from your cylinder to adjust your buoyancy so you're neutral ("weightless"), negative (sink) or positive (float). BCD includes the harness system that holds the cylinder on your back.

- Weight system (integrated into BCD): Holds lead weights to offset buoyancy so you can descend, with a quick release mechanism for dropping the weight in an emergency.

- Dive computer: Tracks your depth and time underwater, calculating your remaining allowable time underwater.

- Compass: Aids underwater navigation.

- Underwater slate: For communicating with another diver or carrying other information.
- Surface signaling devices: Attracts the dive boat's attention if you surface a distance away.

- Recreational Dive Planner dive tables: For dive planning and backup in case of a computer problem.

\subsection{Technical Equipment Defined}

- Mask: Compact for minimum resistance in the water.

- Backup mask: Carried in pocket in case of loss or damage to primary mask.

- Primary regulator: Has two metre/seven foot hose

- for sharing gas with a team mate in an emergency.

- Secondary regulator: Totally independent breathing regulator for use in case of malfunction in primary regulator. Also used if sharing gas with a team mate via the primary regulator.

- SPG, Submersible Pressure Gauge: shows you how much gas you have left.

- Twin cylinders: High capacity cylinders that hold high pressure compressed air, enriched air or trimix depending upon dive requirements.

- Dry suit: Provides insulation for a comfortable dive over a long duration.

- Fins, large size: high power types for propelling yourself laden with tec gear.

- Z-knife (on gauge strap): Specialized knife for freeing yourself in case of entanglement.

- Shears (in sheath on waistband): Backup cutting tool with broader application than z-knife.

- Harness: Shoulder, waist and crotch strap assembly that holds cylinders on your back, with D-rings mounted on the shoulders and at the waist for clipping equipment.

- Wing-type BCD: High capacity BCD with backup gas bladder mounts between harness and cylinder; backup required because in tec diving, you may be too heavy to swim to the surface if your BCD fails.

- Safety reel and lift bag: Deployed to the surface to mark your location and provide a decompression reference; may be a planned dive procedure or an emergency procedure. (Lift bag not visible.)

- Weight system (not shown): Often not needed, but if used, has a double buckle quick release mechanism that allows dropping the weight in an emergency, but prevents accidentally dropping weights.

- Multigas dive computers: Track and display your decompression requirements, these allow you to switch to different kinds of gas blends to optimize decompression. Two worn to provide backup in case of a failure.

- Decompression cylinder/stage bottle: Independent cylinder and regulator carried clipped to your harness on the side. Used to extend dive time and/or to carry a gas for optimizing decompression. Two commonly used, though very complex tec dives may use more.

- All carried in thigh pocket Compass: Aids underwater navigation.

- Underwater slate: For communicating with another diver or carrying other information. 
- Surface signaling devices: Attracts the dive boat's attention if you surface a distance away.

- Backup dive tables: Used to determine decompression requirements in case of a computer problem.

\subsection{The Fully Equipped Commercial Diver}

1. Commercial diving helmet: Fully covers your head and provides air/breathing gas from a surface umbilical on demand; includes speakers and microphone for voice communication

2. Umbilical: Surface supplied gas hose, communications wires and reinforcing safety line bundled together to form a cohesive single line from the surface to the diver. If diving in a hot water suit, the water lines from the surface are also part of the umbilical.

3. Dive control manifold (not shown): Operated by the dive tender, this manifold controls the gas flow to the diver and includes the two-way voice communication system.

4. Bailout bottle (on back): Connected into the diver's breathing system, the bailout bottle provides an emergency gas supply in case of a problem with the surface supply.

5. Dry suit:Although some commercial diving takes place in wet suits, the vast majority takes place in heavy duty dry suits. Very cold water or long dives call for a hot water suit, which provides thermal protection by surrounding you with heated water from the surface.

6. Harness: Provides secure attachment point for the umbilical and the bailout bottle.

\section{Physics of Diving}

Few experiences can compare with the thrill of exploring underwater. Why? Part of it, at least, is that you're adapted to life on land. You're used to the phenomena that surround you. As terrestrial organisms go, you're pretty big, which means you can't fly without the help of a machine, and, generally speaking, falling hurts. A temperature of $24^{\circ} \mathrm{C} / 75^{\circ} \mathrm{F}$ is warm enough to go all day in shorts and a T-shirt. You can determine the direction a sound comes from, and a ripe red apple looks red whether it's 3 metres/10 feet away or 30 metres/100 feet away.

As a diver, though, you enter a domain with a new set of rules. Despite your size, you "fly" in three dimensions and you don't fear falling. Without a wet suit, $24^{\circ} \mathrm{C} / 75^{\circ} \mathrm{F}$ chills you quickly. Most noises sound like they're directly overhead, no matter where they really are. The colors you see vary with depth and distance. And, there are other physical differences that are not obvious to your senses, but vitally affect your safety.

While the physical properties of the underwater world may sometimes appear puzzling, they follow the same laws that govern physics in the rest of universe (at least as far as we know). Because of this, understanding the properties of water and their effects on us only requires understanding some simple principles of chemistry and physics.

Unfortunately, the terms "chemistry" and "physics" can cause undue apprehension among those who feel uncomfortable with mathematics and science. If you're picturing scientists babbling incomprehensible jargon and impossibly difficult equations, forget it. You don't need a $\mathrm{PhD}$ to understand the physical properties of the underwater world.

In continuous, we brief review on some Physics concepts for divers.

\subsection{Matter}

Matter is the substance that makes up all material in the universe. Aside from the results of nuclear reactions (which change matter into energy), matter cannot be created or destroyed. It can, however, be changed from one form to another. Types of matter can combine to form other types with differing properties, and types of matter can break apart to form new types. It can change from one state to another. However, the amount of matter never changes in these processes, which neither create nor destroy matter.

\subsubsection{Types of Matter}

All matter can be broken down into distinct forms, called elements. By definition, an element is a substance that cannot be decomposed into any simpler substances by chemical process. An element is the most basic form of distinct matter.

Nuclear processes can change matter into energy, which is the principle of atomic energy. You may have heard Albert Einstein's famous equation:

\subsection{2. $E=m c 2$}

In his equation, $\mathrm{E}$ stands for energy, $\mathrm{m}$ stands for mass (matter) and c2 stands for the speed of light squared. Since the speed of light squared is a really big number, Einstein's equation shows that a very tiny amount of matter converts into a very large amount of energy. This is the foundational principle behind nuclear energy - whether in a reactor powering an attack submarine or in the sun powering life on earth.

\subsection{Energy}

Energy is the capacity to do work. That's a good definition, but what, then, is work? Work is the application of a force through a distance.

In the metric system, we measure force in terms of ergs and joules. An erg is the amount of work needed to move one gram one centimetre against the force of gravity (gravitational acceleration); a joule is 107 ergs. In the imperial system, we measure energy in terms of foot-pounds. A foot-pound is the amount of work done by a one-pound force, when the point on which it acts moves through a distance of one foot. One joule equals approximately .7375 foot-pounds.

\subsubsection{Types of Energy}

Energy, like matter, can neither be created nor destroyed, though it can convert into matter in a nuclear reaction. In diving, we're concerned with energy's transformation into one of its five forms: 


\section{Heat}

Heat is the motion of molecules and atoms that make up a substance. The more motion, the greater the heat energy, and vice versa. All energy eventually turns into heat. The process of converting energy from one form to another, such as from electrical energy into light energy in a flashlight, always causes some of the energy to dissipate as heat.

2. Light

Light is energy in the form of electromagnetic radiation. The best example is the light energy from the sun. An example of energy transformation is photosynthesis in plants, which transforms light energy into stored chemical energy.

3. Electrical

Electrical energy results from the interaction of negatively charged electrons and positively charged protons. A battery is a good example; it stores potential electrical energy until used in an appliance, such as a flashlight.

4. Chemical

Chemical energy is stored within a substance's molecular composition. A common example of this is gasoline. When it reaches a critical temperature, gasoline reacts with oxygen in a chemical reaction that releases heat energy.

\section{Mechanical Energy}

Mechanical energy results from motion or the possibility of motion - it is the result of an object's position or condition. If an object is retained in a position so that, if released, it could do some sort of work, the object is said to have potential energy. Once in motion, the object is said to have kinetic energy. An example of both types can be found in a spring. When in its static, tense position, the spring has potential energy. Once in motion (either expanding or contracting) the energy is kinetic, that is, released and in motion.

\subsection{Water}

\subsubsection{Water and Heat}

\section{Heat Capacity}

Water's polar molecule gives it important properties related to heat, the first of which is that water has one of the highest heat capacities of all naturally occurring substances (ammonia is one of few exceptions). Heat capacity is a measure of the amount of heat that must be added or removed from a substance to make it change temperature a given amount. Compared to water, for example, air has a very low heat capacity. This is why $24^{\circ} \mathrm{C} / 75^{\circ} \mathrm{F}$ is warm and comfortable in air, but quickly becomes chilly and uncomfortable in water. Air cannot carry heat away from your body as fast as the same temperature water can.

The high heat capacity comes from the polar bond in water. When heating water, a significant amount of heat energy must first break the bonds before heat can increase the kinetic energy (temperature) of the water molecules. Because of polar bonds, water evaporates more slowly than any other common liquid. This phenomenon is referred to as having a high heat of vaporization. The high heat of vaporization occurs because for water to evaporate, sufficient heat energy must be introduced to break the polar bonds between its molecules. Similarly, water has a high latent heat of fusion. This means that when water freezes, it releases large quantities of heat. When ice melts, the water absorbs large quantities of heat. Again, all of these properties result from water's polar nature.

Because of water's high heat capacity, it plays a crucial role in moderating the world's climates. The major oceanic currents carry heat from the warmer equatorial regions toward the cooler regions closer to the poles. This process makes the tropical areas milder and the upper latitudes warmer. An excellent example of this is Bermuda, which enjoys a moderately tropical climate thanks to the Gulf Stream, despite being at about the same latitude as North Carolina in the US. Another example is the Galapagos Islands in the Pacific Ocean off Ecuador, South America. Cold, deep water currents upwell around the islands, absorbing heat from the atmosphere. This gives the island a very cool climate despite being close to the equator.

Water's heat capacity also explains why the temperature variation within a body of water is always less than within a similar volume of air, and why temperature changes take longer in water. You may notice this when diving over the course of a week or so - the air temperature may heat up or cool down one or more times, but the water temperature varies relatively little.

Water and Ice. Water and heat interact in another way that departs from the "typical" substance. As most other liquids cool, they become denser and turn into solids. The liquid transitions into the solid state as the molecules slow and get closer together. The liquid becomes denser as the temperature drops. As it turns into a solid, it becomes denser still, so that the forming solid sinks and accumulates on the bottom of the liquid. The liquid becomes solid from the bottom up.

Water doesn't do this, and it's a good thing for all of us. As it cools, water becomes more dense like any other liquid, but only until it reaches $4^{\circ} \mathrm{C} / 39^{\circ} \mathrm{F}$. At this point, water begins to solidify into ice, but the polar molecules force the molecules into a crystal pattern that takes up more space than it does as a liquid. This means that, unlike most substances - which are denser in their solid form than in their liquid form - solid water (ice) is less dense than liquid water, which is why ice floats.

Besides making ice diving possible, this property is a major influence on the world's climate. Floating ice tends to insulate and retain heat in the water beneath it, slowing the freezing process compared to other liquids. If ice sank rather than floated, massive portions of the oceans would be frozen solid. In fact, most of the earth's water might be frozen.

\subsubsection{Water and Light}

The human eye sees by collecting light reflected from an object, converting this energy into nerve impulses and transmitting them to the brain for interpretation. Since the behavior of light changes as it passes through water, water 
affects how far you can see, clarity, colors and apparent distances.

\subsubsection{Color Absorption}

To understand color absorption, it helps to start with the nature of light and how your eye perceives it. Light is a form of electromagnetic energy and therefore travels in waves; the length of light waves is determined by their energy. Wavelength determines how we classify the type of electromagnetic energy (e.g., x-ray, radio, visible light, etc.). Some wavelengths of electromagnetic energy are not visible, such as ultraviolet light, infrared light, $\mathrm{x}$-ray, microwaves and cosmic rays.

Our eyes see only a narrow segment of the entire electromagnetic spectrum - the wavelength range from about 400 nanometres $(\mathrm{nm})$ to about $760 \mathrm{~nm}$. Differences within this range we perceive as colors. When white light (white light consists of all the perceivable wavelengths) strikes an object, the object absorbs some wavelengths and reflects others. We see the color of something based on the light wavelengths it reflects. If an object reflects all wavelengths, we say the object is white. If it reflects no wavelengths (absorbs all visible wavelengths), we say the object is black.

Wavelengths relate to the amount of energy in light. Colors on the red end of the visible spectrum have less energy than colors on the blue end. Looking at the full spectrum (visible and invisible), infrared light is very low energy and ultraviolet is very high energy.

Even when it's very clear, water absorbs light passing through it, transforming it into heat. However, water doesn't do this uniformly because wavelengths with less energy absorb more easily. Therefore, it absorbs colors toward the red end of the visible spectrum more rapidly than at the blue end. This is why red tends to disappear very quickly as you descend. Usually you don't see much red below 4 metres/15 feet because little light of that wavelength reaches any deeper. This doesn't mean that the color red suddenly blinks out at 4 metres/15 feet, but that practically speaking, red is gone. Color absorption is a continual process, so there's less of all colors at 2 metres $/ 6$ feet than at 1 metre/ 3 feet. This gradual filtering process affects the weaker wavelengths faster.

In order following red, water more readily absorbs orange, yellow and green. The loss of color is why underwater photographers use flash even in very bright conditions. The light from the flash doesn't travel through much water, so it restores the absorbed wavelengths for a colorful picture. This is necessary for good quality underwater photos, even with modern digital cameras that can partially correct for color absorption (more about this later).

As divers, we tend to think of color absorption in terms of depth, but it is actually a function of the total distance light travels through water.

\subsubsection{Refraction}

Another property of light that concerns you underwater is refraction, which is a change direction when light passes from a medium of one density to a medium of a differing density like from air to water or vice versa. Refraction occurs because the speed of light changes with the density, causing a shift in the light's path. The only time the light doesn't shift when it goes from one density to another is when it passes into the new medium at an angle directly perpendicular to its surface. Although refraction differs for each substance light enters, we know its characteristics for most substances - particularly air and water.

In diving, we're most concerned with the refraction that results when light passes from water through glass into the air in your mask or camera housing. As a result of refraction, objects underwater are magnified so they appear closer by a ratio of about 4:3 for their actual and apparent distances. For instance, a fish that's actually four metres/yards away will appear to be three metres/ yards away. You can say, then, that an object appears to be 25 percent closer than it actually is, or 33 percent larger than it actually is. New divers sometimes miss when reaching for something due to this refraction; with experience, most divers learn to correct unconsciously. The magnification effects of refraction may not affect apparent distance, but apparent size. Whether you perceive the object as closer or bigger depends on how your mind interprets the image - either as the actual size but closer, or at the actual distance but bigger. Influences such as distance cues, visibility and your familiarity with the environment and what you're looking at will all affect how your brain interprets what it sees. Generally, an underwater camera sees just like you do with your mask. This is why you have to focus on the apparent distance, not the actual distance of your subject (auto focus systems will do this automatically). The magnification caused by refraction reduces the angle the camera sees, causing a slight telephoto effect. Most underwater photography calls for shooting with as wide an angle as possible, however, so you may see camera housing with dome ports. This relates directly to refraction, or, more precisely, eliminating it. Recall that a light ray does not refract when it enters a medium with a differing density at a perpendicular angle. With a dome port, all the light going into the lens strikes the port at a perpendicular angle. This eliminates refraction and maintains the wide angle of view you want underwater. Although you eliminate refraction, however, a dome port makes the point of focus artificially close - typically around a metre/three feet away - but this isn't a major issue because you focus (or the camera autofocuses) on the apparent distance.

Another effect of refraction is the constantly changing light ripples appearing on the bottom. You notice these ripples easily on flat, sandy bottoms. They're caused by a lens effect of surface waves. As a wave passes overhead, the cresting portion refracts light and concentrates it as bright areas that move across the seafloor with the wave.

\subsubsection{Visual Reversal}

Although refraction makes things look closer than they are underwater, turbidity can make them look farther away than they actually are. This is called visual reversal. Visual reversal results from your visual processing and how your brain interprets what it sees depending upon water clarity, contrast and the amount of light. 


\subsubsection{Reflection}

When light strikes something, it may bounce off or reflect. Whether light reflects depends primarily on the object's color. If it's black or very dark colored, it will reflect relatively little light. If it's white or a very light or pale shade, it will reflect a lot. If it's reflective enough - like a mirror - it's color or shade will appear to be exactly the same as the light striking it because it reflects almost all the light.

\subsubsection{Water and Sound}

Like light, sound is an energy form that travels in waves. Unlike light, however, sound is a form of mechanical energy whereas light is electromagnetic energy. This is significant because electromagnetic energy can exist apart from matter and travel through a vacuum. Sound and other mechanical energy can only exist in and travel through matter.

Sound results when something sets in motion a wave or pattern of waves in matter. The wave or wave pattern may transmit into another medium, such as a noise underwater transmitting through the bottom of the boat and then into air. When the waves vibrate air or water in contact with your eardrum, your ear converts some of the energy into nerve impulses that you perceive as sound.

Sound can travel through any form of matter. Generally speaking, it travels best in dense media like solids and liquids. This is partly because denser material has more tightly packed molecules to transmit the sound wave from one to the next. However, it's not really the density but the elasticity of a substance that allows it to transmit sound more effectively. Think about sending a wave down a taut rope by snapping it compared to doing the same with a taut rubber band. A wave travels along the rubber band faster and farther because of its elastic quality. Since in nature dense materials usually have superior elasticity, it's common to associate good sound transmission with high density. While this is a usable rule of thumb within the scope of diving purposes, remember that it's not technically or universally accurate. Lead and carbon, for example, are quite dense but don't transmit sound well because they have little elasticity. Similarly, a blanket has greater density than air, yet hanging one in a room absorbs sound rather than transmits it. This is because most fabrics have poor elasticity.

The speed of sound depends on the matter through which it travels, influenced by temperature and pressure in many cases. Sound cannot travel in a vacuum at all (absence of matter, as mentioned). In air at sea level at $0^{\circ} \mathrm{C} / 32^{\circ} \mathrm{F}$, sound travels at about 332 metres/1087 feet per second. In fresh water at $15^{\circ} \mathrm{C} / 58^{\circ} \mathrm{F}$, the speed is approximately 1410 metres $/ 4625$ feet per second, while seawater at the same temperature it's approximately 1550 metres $/ 5084$ feet per second.

The reason you often can't tell where a sound is coming from underwater is that the speed of sound is about four times faster than in air. Your brain determines sound direction based on the slight difference in intensity and time at which a sound reaches each of your ears. Underwater, the intensity and time are the same (as far as your brain can tell), which you perceive as being directly overhead. This isn't always the case, though.
Depending on the sound frequency, distance from the source, intensity and other variables, sometimes you can determine a sound's direction reasonably accurately underwater.

While sound will transmit from one medium to another, it resists transmitting through media of differing densities. When sound travels from air into water or vice versa, for example, it loses much of its energy crossing the interface between air and water. This is why you may not hear someone shouting to you even when you're less than a metre or yard under the surface.

The resistance to transmission due to differing densities can apply to a single medium. As you read earlier, water will form layers due to differing temperature and/or dissolved salts. Sound resists traveling between the layers due to their differing densities. A thermocline or halocline can greatly affect sound transmission so that you may readily hear a sound quite well while in the same water layer, yet find it harder to hear the same sound only a short distance above or below the source in a different water layer. How significantly water density affects sound transmission depends on the degree of density change and the sound. However, the differences can be enough that military submarines will descend into a deeper, denser water layer to help avoid detection by sonar.

The resistance to sound transmission from air into water is one reason why you can't readily talk to another diver underwater in most circumstances. Your vocal cords produce sound in air, but it's difficult to transmit enough sound energy into the water to overcome the noise of your regulator and bubbles. Electronic underwater communication equipment overcomes this problem because it turns your voice into a signal that your buddy receives electronically, but in essence this is underwater two-way radio, not the human voice carried through water.

If you become trained to dive with closed-circuit rebreathers, however, this changes somewhat. The sound of your voice still resists transmission from air into water, but a rebreather is very, very quiet. Even without any special equipment, you and a buddy can talk to each other, to some extent, if you speak loudly and stay reasonably close.

\section{The Physiology of Diving}

Of all the life forms on earth, we are the only ones with the means to leave our intended environment for more than a few brief moments. Technology rockets us into space and plunges us into the depths of the oceans.

We venture into realms our bodies weren't designed or equipped for. Compared with other technological adaptations, though, diving stands apart. In many endeavors, machines for exploring other environments isolate and protect us. The space suit shields you from the vacuum; it does not actually allow you to survive in it. A pilot doesn't fly, but rather controls a machine that flies.

Scuba diving differs: you function within a new environment within physiological limits it imposes. Scuba equipment does not breathe for you, but allows your respiratory system to function underwater. Fins don't move 
you, but adapt your feet so you can move yourself.

Technology meshes your physiology with the underwater world. Outwardly, you're a diver because of your training and equipment.

Inwardly, you're also a diver because your physiology responds and adapts to the demands of the underwater world.

This adaptability to a new environment is all the more remarkable considering how intricate and complex your body is: literally billions of cells - each a single unit of life - work interdependently to coexist as complex tissues, organs and systems, each with a specific purpose, to create a complex, single unit greater than the sum of its parts: you. Yet within this marvelous, unlikely complex structure, your body functions according to the same clear, simple principles that govern the rest of nature. What makes your body remarkable is how these thousands of basic and simple actions occur simultaneously to maintain life.

Diving physiology studies the way your body functions underwater. It's a look at the responses your body takes to changes caused by the underwater environment, as well as the problems and their consequences that result when your body can't respond or adapt, or does so ineffectively.

\subsection{Dead-Air Space}

Dead-air space (also known as dead space) is the portion of your tidal volume that plays no direct part in gas exchange. Without equipment, dead-air space consists of your sinuses, trachea and bronchi. Equipment, however, adds the additional volume of the snorkel, regulator or other breathing equipment to your dead-air space. (Note: Although called dead air, this response pertains to any gas blend you use while diving).

When you inhale, the first gas drawn into your alveoli is the gas left in your breathing passages from your previous expiration. This gas is high in carbon dioxide and mixes with the fresh gas you inhale, so that your alveolar gas is always a bit higher in carbon dioxide than the fresh gas you're breathing. Adding a snorkel, regulator or other breathing device increases the amount of dead air you inhale. Another factor is that being in water reduces your tidal volume about 15 to 20 percent (more so when you're vertical in the water than when you're horizontal) due to pressure compressing your thorax.

With your tidal volume decreased and your dead-air space increased, dead air becomes a larger proportion of each breath, raising the carbon dioxide in your alveoli correspondingly.

How much the carbon dioxide increases depends upon your tidal volume and the dead-air space volume, so it can range from insignificant to substantial. Within limits, you compensate for the higher carbon dioxide through both an involuntary and a voluntary response.

Increased alveolar carbon dioxide raises carbon dioxide in your bloodstream, but there's no substantial decrease in the oxygen level. Nonetheless, due to elevated carbon dioxide your reflex respiratory center stimulates you to breathe more frequently and/or more deeply. Physiologists have found that in some divers, the reflex respiratory center learns to tolerate a slightly higher-than-normal carbon dioxide level. This seems most pronounced among divers who make long breath-hold dives, such as when hunting underwater or in competitive free diving (we'll look at how your body responds to breath-hold diving shortly). So, while your involuntary response may be to breathe deeper and faster, with experience and within limits this response may diminish.

Your voluntary response - one you make consciously - is to breathe deeply to maximize your tidal volume. By taking advantage of as much volume as possible per breath, you reduce the proportion of dead air reaching your alveoli. This is one reason why you're trained to take slow, full breaths while diving.

Another response involves equipment design. Manufacturers design underwater breathing equipment to minimize the effects of dead-air spaces. As you read in Chapter Three, this is one reason why you don't find many manufacturers making excessively long snorkels anymore they unnecessarily increase dead-air space. Many fullface masks and commercial diving helmets have oral/nasal masks or pockets that isolate the mouth/nose from the rest of the mask.

This is to reduce the effective dead-air space and carbon dioxide accumulation within the mask. The typical recreational regulator second stage, however, has such a low volume that it adds less deadair space than your average snorkel.

\subsection{Gas Density}

While diving with breathing equipment, your deep breathing requires an additional voluntary adaptation as a consequence of the denser air (or other breathing gas) at depth.

The denser a gas becomes, the less smoothly it flows at a given speed. All else being the same, as the speed increases, breathing resistance increases disproportionately. That is, it takes more than twice as much energy to inhale and exhale a given volume twice as fast.

This is because when gas flows through smooth passages, it can travel with an uninterrupted, laminar flow. This means it generally moves as a continuous column. Unfortunately, you're not breathing through smooth passages, but through dive equipment, your trachea and bronchi. In these rough passages, the flow becomes turbulent from friction between the gas and the passage sides. This drag causes the gas to move faster in the center of the flow column than at the sides, leading to swirls that rotate away from the flow direction, disrupting smooth flow and increasing resistance. The denser the gas, the more disruption you have at a given flow rate.

To a degree, this resistance has a benefit (even at the surface) in that it causes a slight pressure increase in the bronchioles and alveoli during exhalation. This increase helps keep the air passages from collapsing after exhalation, although a percentage will still collapse after each breath, whether you're at the surface or underwater. We'll look at how air-passage collapse affects diving under Physiological Responses to Pressure Change on Body Air Spaces. 


\subsection{Responses to Breath-Hold Diving}

While breath-hold diving, your body responds to apnea (cessation of breathing) to ensure that you survive and that you eventually resume breathing. Physiologists have found that your body responses differ in some respects when you hold your breath in water compared to doing so on land, though it's still unclear to what degree and why.

During apnea, your circulatory system taps oxygen stored in your lungs, muscles and blood to supply tissue oxygen needs. With no place to vent, as time goes by carbon dioxide builds in the circulatory system, your lungs, muscles and other organs. The rising carbon dioxide causes your reflex respiratory center to stimulate the diaphragm, which you feel as the urge to breathe.

The initial urge is weak, but successive urges grow stronger as your body consumes oxygen and produces carbon dioxide, until you must surface for air. How long you can go without breathing depends on several physiological variables and responses, not all of which physiologists completely understand.

The extent of these responses varies significantly from individual to individual, which is why some divers can hold their breath much longer than others. Several responses in your body extend how long you can hold your breath in water. One of these, many physiologists believe, results from the effect of water pressure. As you descend, water pressure compresses the air in your lungs, raising the oxygen partial pressure. This elevated PO2 allows your blood to use more of the remaining oxygen within your lungs than would be possible at surface pressures.

An involuntary response found in breathhold diving is a predictable change in your heart rate. When you first take a deep breath, tachycardia, or speeding up of the heart rate occurs, followed bradycardia, or slowing of the heart rate. Studies have also found arrhythmia (irregular heart beat) during long breath-hold dives by trained free divers.

The bradycardia response to apnea has sometimes been called the mammalian diving reflex because it is found in diving mammals such as whales, seals and porpoises. The diving reflex in humans is believed to have helped prevent deaths in near-drowning accidents of youths in water below $10^{\circ} \mathrm{C} / 50^{\circ} \mathrm{F}$

In such incidents, near-drowning victims have recovered with resuscitation, even after periods of 20 minutes or more without breathing and without apparent after effects.

Physiologists don't fully understand how or why the diving reflex works. They know that it is associated with cold moisture on the face, but in studies cold water does not always lead to longer breath-hold times. That cold water on the face seems to trigger the response explains why the diving reflex has been noted less in warm-water near-drowning accidents.

It appears the diving reflex pools blood in the brain and heart, distributing the limited oxygen supply only to critical areas. This may relate to rising carbon dioxide, which your

body responds to by reducing blood flow to the extremities (peripheral vasoconstriction) and increasing it to the brain (cerebral vasodilatation). Unlike marine mammals, which have a constant blood pressure during apnea, human blood pressure increases with apnea duration. Changes in circulation patterns also result as natural responses to temperature; some physiologists think that

diving reflex circulation patterns may be partially attributable to normal responses to cold.

Besides involuntary responses, you can increase breath-hold time through voluntary responses. The first of these is to relax and minimize effort. The less you exercise and exert yourself, the more slowly you consume oxygen and produce carbon dioxide. A second voluntary response is to practice.

Studies suggest that trained freedivers can hold their breath longer because they become more tolerant to carbon dioxide and have improved anaerobic capacity - that is, the body improves the processes it uses to provide energy in the absence of oxygen. Your third voluntary response is to start a breath-hold dive with less carbon dioxide in your system. You do this by intentionally hyperventilating with three or four deep, rapid breaths prior to holding your breath. By doing this, you reduce respiratory carbon dioxide levels below normal, which in turn drops your circulatory carbon dioxide levels. This means your tissues can produce more carbon dioxide than normal before reaching the level that stimulates breathing As you'll see in the next section, however, it's important that you limit hyperventilation to no more than three or four breaths.

\section{Cause of Gas Narcosis}

Like many aspects of dive physiology, with narcosis we seem to know more about what happens than why. The exact mechanism surrounding narcosis is not fully understood, but we do know that almost any gas can cause anesthesia under high partial pressures, including inert gases.

Physicists describe nitrogen gas as a physiologically inert gas. This doesn't mean that nitrogen is completely inert (it's not - it takes part in many chemical reactions), but that nitrogen gas doesn't have any chemical reactions within your body. None of the nitrogen you breathe is used to build protein or enzymes (that nitrogen comes from food).

Inert doesn't mean there's no effect. For example, when nitrogen dissolves into your tissues during a dive, if it comes out of solution too quickly upon ascent, it can form bubbles and cause decompression sickness (discussed in detail at the end of this chapter). Dissolved in brain tissue, inert and non inert gases, including nitrogen, can act as an anesthetic. You can compare narcosis while diving with another narcotic gas, nitrous oxide. Nitrous oxide (sometimes called "laughing gas") is a commonly used surgical anesthetic, particularly in dentistry, because it is narcotic at sea level. In high concentrations it causes euphoria, drunkenness and, in a very short time, unconsciousness. These effects are pressure-related. If you double the pressure, you roughly double the effect.

The narcotic potential of a gas is approximately proportional to its solubility in lipids (fats). Using this guideline, helium is only a fifth as narcotic as nitrogen, while 
carbon dioxide is 20 times and oxygen is 1.6 times as narcotic as nitrogen. However, human tests show that you can't measure narcosis this simply.

An intriguing gas with respect to gas narcosis is oxygen. Deep dive tests (91 metres/300 feet) have shown that a blend of four percent oxygen/96 percent nitrogen is more narcotic than air, rather than less as you would expect based on oxygen having higher lipid solubility than nitrogen. Nonetheless, several other test series show that increased PO2s in the presence of nitrogen do increase narcosis. Most dive physiologists explain this apparent contradiction by concluding that there's a yet-to-be-determined narcotic relationship between nitrogen and oxygen.

While it's clear that oxygen does contribute to narcosis (which is why you treat air and enriched air as equally narcotic), its narcotic potential doesn't appear to be related simply to its solubility in lipids.

Carbon dioxide is another gas that contributes to narcosis. Multiple studies show that increases in carbon dioxide - either in the breathing gas or accumulating within your respiratory system due to dead-air and breathing dense gases - increases narcosis. The mechanism is even less clear than with oxygen; some tests suggest carbon dioxide is about 10 times as narcotic as nitrogen - not the 13 to 20 times you would expect based on its lipid solubility.

\section{Conclusion}

Diving is one of the exciting water sport and many people refer for recreation or training to the required centers.

In this paper, we a brief reviewed on PADI encyclopedia of recreational diving, which will be useful for the researchers who are professional and interested in this area, and also useful for person who have fun dive. We described advantages of knowing each section throw of that section.

\section{References}

[1] Www.Padi.com

[2] The Encyclopedia of Recreational Diving \& Diving Knowledge Workbook, PADI Americas, Inc., 30151 Tomas Street, Rancho Santa Margarita, CA 92688-2125 USA.

[3] T. Hajjari, M. Ali Beigi., Research Method, Report and Thesis Writing, Fraranama Publishing (In Persian), 2012.

[4] Akyildiz, I. and Su, W. and Sankarasubramaniam, Y. and Cayirci, E., "A Survey on Sensor Networks", IEEE Communications Magazine, vol 40, Issue 8, pp. 102-114, 2002.

[5] Bachrach, Arthur J. (1988). A PICTORIAL HISTORY OF DIVING, Best Publishing Company, San Pedro, California, USA.

[6] Bagherian, Mohamamd Rasul, 2007. The comprehensive guide of diving in high water. Tehran. Mahsa.

[7] Bagherian, Mohammad Rasul. 2009. The comprehensive guide of advanced diving, Tehran: Pazine.
[8] Ballard RD. Epilogue for Titanic. National Geographic, Vol. 172, October 1987, page 454.

[9] Billings, Henry. (1956). MAN UNDER WATER, Lutterworth Press, London.

[10] Brylske, A., Brief History of Diving, Parts I and II. Dive Training Magazine. August \& September 1994.

[11] Cardone, B, editor. The Fireside Diver. Menasha Ridge Press, Birmingham, 1992.

[12] Carlisle, N., Riches of the Sea. Sterling Publishing Co., New York, 1967.

[13] Cousteau, JY., and Dumas, F., The Silent World. Ballantine Books, New York, 1953.

[14] Cousteau JY, with Dugan J. The Living Sea. Harper \& Row, New York, 1963.

[15] Cousteau, JY., Dugan, J., World Without Sun. Harper \& Row, New York, 1965.

[16] Crichton, M. Spere. Alfred A. Knopf, New York, 1987

[17] Cussler, C., Pacific Vortex. Bantam Books, New York, 1982.

[18] Davis, J., Bikini's Silver Lining. NY Times Magazine, May 1, 1994. Pg. 43.

[19] DeLoach, N., Eagles Fly Alone. aquaCorps N8, 1994; page 65.

[20] Dugan, J., Man Under the Sea. Harper \& Brothers, New York, 1956.

[21] Dugan, James. (1956). MAN EXPLORES THE SEA, Great Britain, by Hamish Hamilton Ltd, London.

[22] Ellis, RE., The Book of Sharks. Alfred A. Knopf, New York, 1989.

[23] Ellis, RE., McCosker JE. Great White Shark. HarperCollins Publishers, New York, 1991.

[24] Ellis, RE., Monsters of the Sea. Alfred A. Knopf, New York, 1994.

[25] Exley, S., Max Head Room. aquaCorps N7, 1994; pages 64-65.

[26] Gilliam, B., Von Maier R. History of Diving, in Deep Diving. An Advanced Guide to Physiology, Procedures and Systems. Watersport Publishing, Inc. San Diego; 1992.

[27] Gilpatric, G., The Compleat Goggler. Saturday Evening Post, October 6, 1934, p. 10.

[28] Groves, D., The Oceans. A Book of Questions and Answers. John Wiley \& Sons. New York, 1989.

[29] Guinness Book of Records, Bantam Books, New York. Published annually.

[30] Hamilton, B., Daughtery, G., Kristovich, A., What happened to Sheck Exley? Pressure November/December 1994 (part 1) and January/February 1995 (part 2).

[31] Hamner, WM., Australia's Box Jellyfish. A Killer Down Under. National Geographic 86:2, August, 1994; p. 116. 
[32] Heinzelman, W., Chandrakasan, A., and Balakrishnan, H., "An Application-Specific Protocol Architecture for Wireless Microsensor Networks", IEEE Transactions on Wireless Communications, vol. 1, no. 4, pp. 660-670, 2002.

[33] Hendrickson, R., The Ocean Almanac. Doubleday, New York, 1984.

[34] Hong, et. al. Daily diving pattern of Korean and Japanese breath-hold divers (ama). Undersea Biomedical Research 1991;18:433-443.

[35] Holliday, L., Coral Reefs. Tetra Press, Morris Plains, NJ, 1989.

[36] Huehner, JC., The Call of the Deep. The Cleveland Plain Dealer, August 2, 1994, page 1.

[37] Leaney, L., The Mark V Column. Historical Diver, No. 2, Winter 1993; p. 17

[38] Madsen, A., Cousteau. An Unauthorized Biography. Beaufort Books Publishers, New York, 1986.

[39] Manion, DJ., IANTD Journal, 9628 N.E. 2nd Avenue, Suite D, Miami Shores, Florida 33138-2767; issue of May-July 1994, page 8 .

[40] Martin, M., Porter M. Video Movie Guide 1995. Ballantine Books, New York, 1994.

[41] Marx, RF, with Marx, J., The Search for Sunken Treasure. Exploring the World's Great Shipwrecks. Key-Porter Books, Toronto, 1993.

[42] Marx, RF., Into the Deep. Van Nostrand Reinhold, New York, 1978.

[43] Marx, RF., The History of Underwater Exploration. Dover Publications, Inc., New York, 1990.

[44] McCullough, D., The Great Bridge. The Epic Story of the Building of the Brooklyn Bridge. Simon and Schuster, New York, 1972.
[45] Munson, R., Cousteau: the Captain and His World. Wm. Morrow \& Co., New York, 1989.

[46] Nichols, G., History of Diving, in Alert Diver, Divers Alert Network, May/June 1993.

[47] Protasio, J., To the Bottom of the Sea. True Accounts of Major Ship Disasters. Carol Publishing Group, New York, 1990.

[48] Roessler, C., Underwater Wilderness: Life Around the Great Reefs. Chanticleer Press, New York, 1986.

[49] Sammon, R., Seven Underwater Wonders of the World. Thomasson-Grant, Inc. Charlottesville, VA, 1992.

[50] Sheard, B., Beyond Sport Diving! Exploring the Deepwater Shipwrecks of the Atlantic. Menasha Ridge Press, Birmingham, AL, 1991.

[51] Sterba, JP., Klutzy Scuba Divers Love the Coral Reefs A Bit Too Vigorously. Wall Street Journal, May 7, 1993. Page 1.

[52] Talyor, MR., Deep, Dark and Deadly. The perils of cave diving didn't spare even the sport's greatest star. Sports Illustrated, Vol 81, No. 14, October 3, 1994.

[53] Toluhonari, Mohsen; Tashtarian, Farzad; Chitizade, Jalil; Rajabi Mashhadi, Habib. 2007. Nodes clustering in wireless sensor networks by genetic algorithm, The first common congress of fuzzy systems and intelligent systems. Ferdoosi University of Mashhad. Mashhad. Iran.

[54] Verne, J., 20,000 Leagues Under the Sea. 1925; Charles Scribner's Sons, New York

[55] Whittingham. The Rand McNally Almanac of Adventure. Rand McNally,Chicago, 1982.

[56] Younis, O., Krunz, M. and Ramasubramanian, S., "Node clustering in wireless sensor networks: recent developments and deployment challenges", Network, IEEE, vol 20, Issue 3, pp. 20 - 25, May-June, 2006.

[57] Zumrick, J., Sheck Exley: Preliminary Accident Report. aquaCorps N8, 994; page 71. 